\title{
ARTICLE
}

\section{Development and Evaluation of Two Different Electronic Tongues Aiming to the Discrimination of Cutting Agents Found in Cocaine Seized Samples}

\author{
Thalita Guedes Silva iD, Thiago Regis Longo Cesar da Paixão* iD \\ Instituto de Química, Universidade de São Paulo, Av. Lineu Prestes, 748, Butantan, CEP 05508-000, São Paulo, \\ SP, Brazil
}

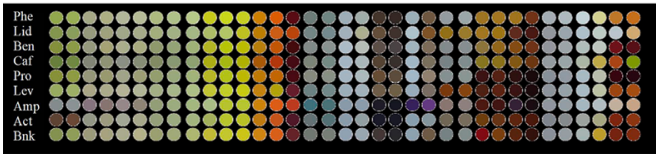

Colorimetric Electronic Tongue

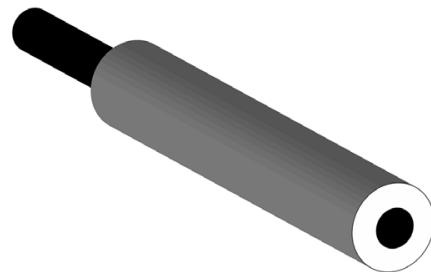

Electrochemical Electronic Tongue
Chemometrics

4 Cutting Agents
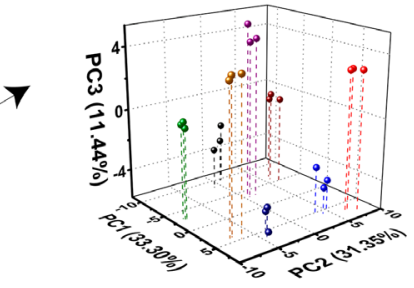

Cocaine Samples

$\Lambda$

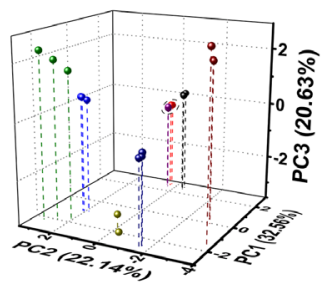

The screening and impurity profiling of drugs, like cocaine, is essential information that provides chemical and/or physical characterization to assist police agencies in understanding the trafficking and identifying drug origin. This work proposes to show the development and applications of two different electronic tongues (e-tongues) on the profiling study of cocaine seized samples. The developed intelligent devices' primary objective is the simple, quick, and remote cocaine classification samples based on the individual cutting agents added. The paper-based colorimetric sensor was fabricated in the lab using chromatographic paper as a substrate, wax printing to produce spot zones of reactions, a smartphone as image detection, and an editing image software to extract the chemical information through RBG values. The voltammetric e-tongue applied a boron-dopped diamond electrode to extract the cutting agents' electrochemical information through the square wave voltammetry (SWV) technique. In any case, both described sensors were coupled to chemometric tools for data analysis to construct the discrimination model. According to the objective, the unsupervised pattern recognition technique, Principal Component Analysis (PCA), was applied to test the capability of the device on individually discriminating the most common cutting agents of cocaine.

Cite: Silva, T. G.; Paixão, T. R. L. C. Development and Evaluation of Two Different Electronic Tongues Aiming to the Discrimination of Cutting Agents Found in Cocaine Seized Samples. Braz. J. Anal. Chem., 2022, 9 (34), pp 188-197. doi: http://dx.doi. org/10.30744/brjac.2179-3425.AR-59-2021

Submitted 12 April 2021, Resubmitted 14 June 2021, $2^{\text {nd }}$ time Resubmitted 20 July 2021, Accepted 30 July 2021 , Available online 25 August 2021. 
Keywords: electrochemical e-tongue, paper-based colorimetric e-tongue, chemometrics, forensic analysis, chemical profiling

\section{INTRODUCTION}

The ever-growing problem of drug consumption requires an increasing need for measurements to identify links and trafficking routes to assist drug intelligence agencies in containing drug markets' expansion. According to World Drug Report (WDR) published on United Nations Office on Drug and Crime (UNODC) in 2020 [1], the COVID-19 pandemic may reflect in the evolution of drug markets as a consequence mainly of the lesser control by the authorities of illicit crop cultivation and the economic crisis which turns more people to illegal activities. The seized drug characterization and impurity profiling are scientific tools to provide helpful information for drug law enforcement investigative work, e.g., classifying materials of related samples and identifying origin and distribution networks. Therefore, drug profiling may create a databank for pattern recognition that supplies a guide for identifying new illicit laboratories and new manufacturing methods, providing great help to the contention process [2,3]. Once the drug market and use situations change rapidly, studies developing techniques to analyze must also be quick and adaptable to the new circumstances.

Among the well-known drugs, cocaine is still one of the most widely illicit substances consumed worldwide [1], affecting mainly the Central Nervous (CNS) and Cardiovascular Systems. Cocaine is a tropane alkaloid and was commonly used as a local anesthetic due to its blocking the sodium channels depolarization, inhibiting impulse transmission and, therefore, the pain stimulus. This drug is a potent stimulant of CNS, inhibiting the catecholamines recapture, promoting euphoria and chemical dependence [4]. Nowadays, cocaine is frequently commercialized on the illicit market with a large variability of chemical composition due to clandestine laboratories and manufacturers' poor conditions [3]. Generally, pharmacological substances with similar properties, called cutting agents, are included in the manufacturing process to enhance or mimic the drug effects, increasing its profits by selling less cocaine [5]. Within this situation, this drug's impurity profiling could be a chemical signature assigned to every drug sample, providing a complete history of the sample as background support to the intelligent agencies [3].

In this context, Electronic Tongues and Noses are powerful tools to provide screening and chemical characterization with a high-quality and quick outcome. The classification of e-devices is related to the sample tested by the device used, like its mammalian analogs (tongue and nose). Liquid samples are evaluated by the e-tongue and gas samples by e-noses. Those devices are a kind of bionic detection approach similar to the mammalian recognition system. In another way, this device consists of a highstability sensor with high cross-selectivity [6], which provides complex information about the sample. Such complex analytic data must be processed by using multivariate data analysis to obtain the expected answer. Seeking to establish the pattern and fingerprinting information to discriminate and classify samples, the e-tongues have been widely used in the research for quality control [7], beverages adulteration and tracking [8,9], environmental monitoring [10], pharmaceutical analysis [11], and medical diagnoses [12]. Several types of e-tongues have been developed based on different principles $[11,13,14]$. Electrochemical and paper-based colorimetric e-tongues systems have received particular attention due to their quick response, flexible application, low cost, and portability to remote analysis $[8,12,15]$.

Commonly, the cutting agent's discrimination in cocaine samples is reported using Raman Spectroscopy [16] and gas chromatography-mass spectrometry [17] associated with multivariate analysis. This technique for detection is time-consuming, needs well-trained persons, and does not show possibilities for in-field applications by the police. Hence, this report presents the development and evaluation of two in-field different electronic tongues, voltammetric and paper-based colorimetric, to identify and discriminate, using non-supervised pattern recognition, the eight most common cutting agents found in cocaine seized samples [18]. All contaminants' individual chemical information was registered and extracted using the electrochemical sensor in the voltammetric technique and a smartphone associated with an image extraction program to develop the colorimetric device. The pattern output was achieved using chemometric analysis. 


\section{MATERIALS AND METHODS \\ Reagents}

The cutting agents benzocaine, caffeine, procaine chloride, levamisole chloride, aminopyrine, acetaminophen, and phenacetin were obtained from Sigma-Aldrich (Steinheim, Germany). Each cutting agent's stock solution was prepared in a mixture $(1: 1 \mathrm{v} / \mathrm{v})$ of water/acetonitrile from Merk (Darmstadt, Germany). To the electrochemical procedures, all stock solutions were diluted in phosphate buffer 0.1 $\mathrm{mol} \mathrm{L}^{-1}$ (pH 6.8) purchased Synth (São Paulo, Brazil). The reagents iron(III) chloride, N-(1-Naphthyl) ethylenediamine dihydrochloride, iodine, potassium iodide, potassium ferricyanide, cobalt sulfate II, silver nitrate, sodium nitrite, potassium meta periodate, sodium carbonate, methyl orange, ammonium metavanadate, sodium benzoate, and sulfanilic acid were obtained from Sigma-Aldrich (Missouri, EUA), Merk (Darmstadt, Germany), Nuclear (São Paulo, Brazil) and Synth (São Paulo, Brazil). The chromatographic paper (JP40) used to fabricate the paper-based device was purchased from JProlab (Paraná, Brazil).

\section{Electrochemical procedure}

All the voltammograms were performed using a common system of three electrodes boron-dopped diamond (BDD), $\mathrm{Ag} / \mathrm{AgCl}$ (Sat)/KCl (Sat.), and platinum as work, reference, and counter electrode, respectively. The BDD surface was electrochemically pre-treated applying amperometry procedure in sulfuric acid $0.5 \mathrm{~mol} \mathrm{~L}^{-1}$ solution: $3.0 \mathrm{~V}$ for the $30 \mathrm{~s}$ followed by $-3.0 \mathrm{~V}$ for $120 \mathrm{~s}$ to surface activation and $3.0 \mathrm{~V}$ for $10 \mathrm{~s}$ followed by $-3.0 \mathrm{~V}$ for $30 \mathrm{~s}$ to ensure a consistent condition of the electrode surface between experiments. Square Wave Voltammetry (SWV) experiments were carried out from 0 to $1.7 \mathrm{~V}$ with the parameters: $\operatorname{step}\left(\Delta E_{S}\right)=5 \mathrm{mV}$, amplitude $\left(\Delta E_{A}\right)=25 \mathrm{mV}$ and frequency $(f)=30 \mathrm{~Hz}$, to extract the chemical information from the analytes.

\section{Colorimetric device}

The spot-test colorimetric experiments were performed using a paper-based system produced in the lab, procedure schematized in Figure 1. A previous pattern of the black background with white circles (diameter $=3 \mathrm{~mm}$ ) was designed using CorelDRAW ${ }^{\circledR}$ for Windows and printed in chromatographic paper using a commercial wax print to produce the reactional zones. The printed paper was thermally pre-treated applying $120^{\circ} \mathrm{C}$ for 3 minutes to fuse the wax printed and making a hydrophobic barrier in all the paper layers. Thus, eight reagent mixtures were immobilized on the constructed paper substrate to finish the device development. The composition of each reagent is found in Table I. Aim to perform the analysis; the device was exposed to the cutting agents' solutions. After $5 \mathrm{~min}$ of reaction, the photographic images were taken employing a chamber coupled to iPhone $4 S$ to provide a fixed focus distance and homogeneous lighting during all the registrations. The chemical information was extracted as an RGB pattern for each cutting agent using GNU Image Manipulation Program (GIMP2).

In this procedure, we evaluated the slopes from the analytical calibration curves for each RGB value to remove the concentration effect in the measurement. This mathematical procedure was necessary once both intensity and color values change with the concentration. Then, the chemometric treatment could detect this information as different samples for a different concentration of the same analyzed compound. Hence, we added the investigated compound in the sample in various concentrations and mathematically calculated the linear regression for each color channel (R, G, and $B)$. Based on this information, the regression slope in each channel was used as input to remove the concentration problem since each cutting agent will have a unique slope pattern in the linear regression. 


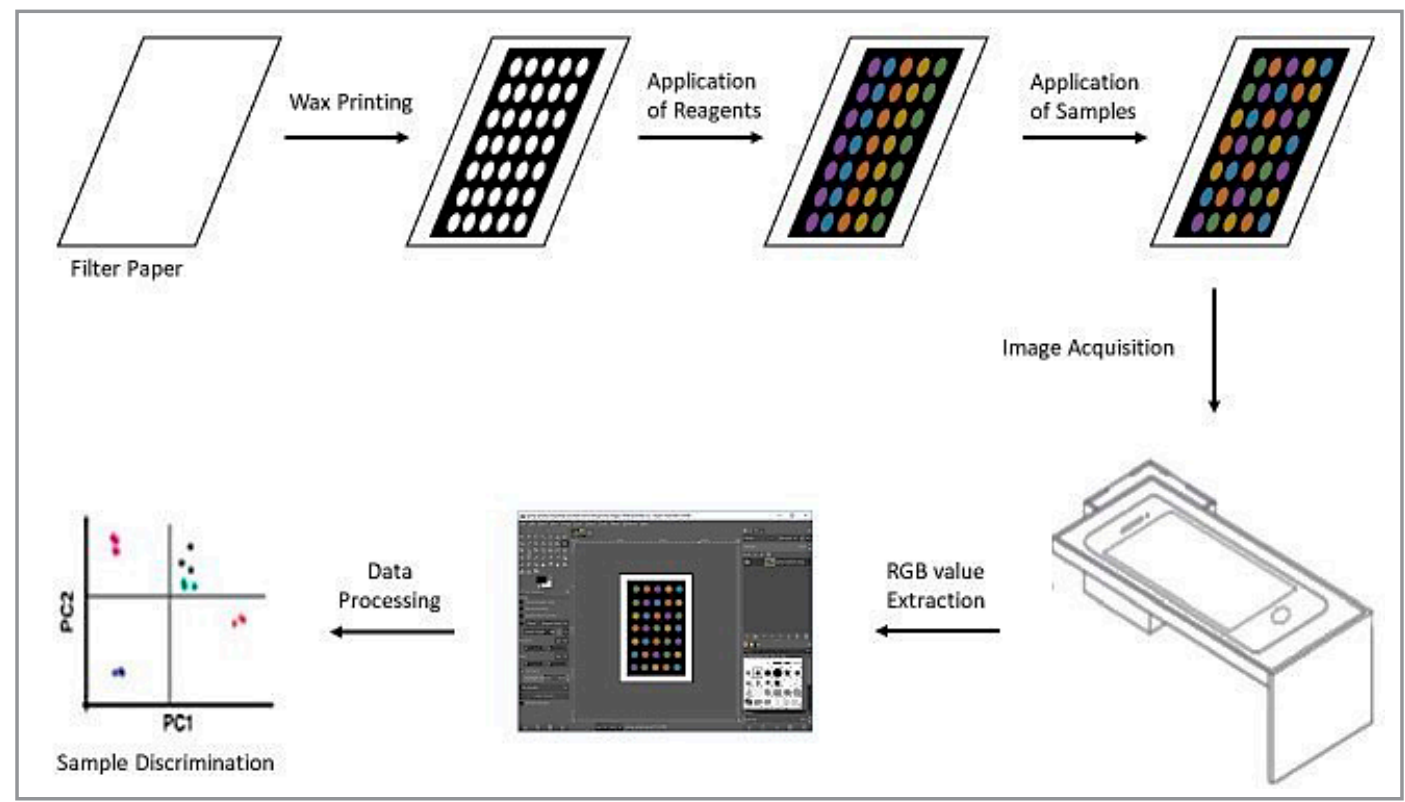

Figure 1. Schematic representation of the measurement process for extracting and analyzing RGB values to discriminate cutting agents in cocaine seized samples.

Table I. Composition of each reagent used in the paper-based-colorimetric device

\begin{tabular}{|c|c|c|c|c|}
\hline Reagent Mixture & Components* & Medium & Oxidant $^{* *}$ & $n^{\circ}$ \\
\hline \multirow{6}{*}{ Bouchardat (Wagner) } & \multirow{6}{*}{$\begin{array}{l}\mathrm{I}_{2}: 8 \mathrm{mmol} \mathrm{L}^{-1} \\
\mathrm{KI}: 24 \mathrm{mmol} \mathrm{L}^{-1}\end{array}$} & \multirow{3}{*}{$\mathrm{NaOH}$} & No & 1 \\
\hline & & & Yes & 2 \\
\hline & & & No & 3 \\
\hline & & $\mathrm{H}_{2} \mathrm{O}$ & Yes & 4 \\
\hline & & \multirow{2}{*}{$\mathrm{HCl}$} & No & 5 \\
\hline & & & Yes & 6 \\
\hline \multirow{3}{*}{ Methyl orange } & \multirow{3}{*}{ Methyl orange: $20 \mathrm{mmol} \mathrm{L}^{-1}$} & \multirow{3}{*}{$\begin{array}{l}\mathrm{NaOH} \\
\mathrm{H}_{2} \mathrm{O} \\
\mathrm{HCl}\end{array}$} & No & 7 \\
\hline & & & No & 8 \\
\hline & & & No & 9 \\
\hline \multirow{2}{*}{ Potassium Ferricyanide } & \multirow{2}{*}{$\mathrm{K}_{3}\left[\mathrm{Fe}\left(\mathrm{CN}_{6}\right)\right]: 20 \mathrm{mmol} \mathrm{L}^{-1}$} & \multirow[b]{2}{*}{$\mathrm{NaOH}$} & No & 10 \\
\hline & & & Yes & 11 \\
\hline \multirow{4}{*}{ Iron III Chloride } & \multirow{4}{*}{$\mathrm{FeCl}_{3}: 20 \mathrm{mmol} \mathrm{L}^{-1}$} & \multirow{3}{*}{$\mathrm{H}_{2} \mathrm{O}$} & No & 12 \\
\hline & & & Yes & 13 \\
\hline & & & No & 14 \\
\hline & & $\mathrm{HCl}$ & Yes & 15 \\
\hline \multirow{4}{*}{ Cobalt II Sulphate } & \multirow{4}{*}{$\mathrm{CoSO}_{4} \cdot 7 \mathrm{H}_{2} \mathrm{O}: 20 \mathrm{mmol} \mathrm{L}^{-1}$} & \multirow{3}{*}{$\mathrm{NaOH}$} & No & 16 \\
\hline & & & Yes & 17 \\
\hline & & & No & 18 \\
\hline & & $\mathrm{H}_{2} \mathrm{O}$ & Yes & 19 \\
\hline
\end{tabular}


Table I. Composition of each reagent used in the paper-based-colorimetric device (Continuation)

\begin{tabular}{|c|c|c|c|c|}
\hline Reagent Mixture & Components* & Medium & Oxidant** & $n^{\circ}$ \\
\hline \multirow{4}{*}{ Silver Nitrate } & \multirow{4}{*}{$\mathrm{AgNO}_{3}: 20 \mathrm{mmol} \mathrm{L}^{-1}$} & \multirow{3}{*}{$\mathrm{NaOH}$} & No & 20 \\
\hline & & & Yes & 21 \\
\hline & & & No & 22 \\
\hline & & $\mathrm{H}_{2} \mathrm{O}$ & Yes & 23 \\
\hline \multirow{6}{*}{ Ammonium Metavanadate } & \multirow{6}{*}{$\mathrm{NH}_{4} \mathrm{VO}_{3}: 20 \mathrm{mmol} \mathrm{L}^{-1}$} & \multirow{3}{*}{$\mathrm{NaOH}$} & No & 24 \\
\hline & & & Yes & 25 \\
\hline & & & No & 26 \\
\hline & & $\mathrm{H}_{2} \mathrm{O}$ & Yes & 27 \\
\hline & & \multirow{2}{*}{$\mathrm{HCl}$} & No & 28 \\
\hline & & & Yes & 29 \\
\hline \multirow{6}{*}{ Sims-Horn } & & \multirow{3}{*}{$\mathrm{NaOH}$} & No & 30 \\
\hline & NED: 5 mmol L-1 & & Yes & 31 \\
\hline & $\mathrm{NaNO}_{2}: 5 \mathrm{mmol} \mathrm{L}-1$ & & No & 32 \\
\hline & Sodium Benzoate: $5 \mathrm{mmol} \mathrm{L-1}$ & $\mathrm{H}_{2} \mathrm{O}$ & Yes & 33 \\
\hline & \multirow[t]{2}{*}{ Sulfanilic Acid: 5 mmol L-1 } & \multirow{2}{*}{$\mathrm{HCl}$} & No & 34 \\
\hline & & & Yes & 35 \\
\hline
\end{tabular}

*Final concentration at the spot. ${ }^{* *}$ Oxidant: Potassium meta periodate.

\section{Data treatment and analysis}

The extracted values of current from SWV were mathematically treated using baseline correction and normalization [19]. The chemometric analysis was performed applying the unsupervised pattern recognition technique, principal component analysis (PCA), using the RGB pattern and the current values extracted from the cutting agents as input data. The chemometrics experiments were performed using Statistica 13.0 (StatSoft Inc., Tulsa, OK, USA).

\section{RESULTS AND DISCUSSIONS \\ Electrochemical experiments}

Cyclic voltammetry (CV) is commonly the first technique used in electroanalytic. It is possible to investigate electronic transfer processes and redox mechanisms due to their quick response to thermodynamic and kinetic parameters from the redox reactions. This work applied CV as an exploratory technique to choose the optimal conditions to extract the electrochemical information from the targets. Work electrode surface and hydrogen ion concentrations are among the varied parameters. Considering the purpose of qualitative study, to discriminate and classify cutting agents, the best signals separation was achieved with the borondoped diamond as work electrode, besides its large potential window that promotes more negligible surface adsorption, and phosphate buffer $0.1 \mathrm{mmol} \mathrm{L}^{-1}(\mathrm{pH} 6.8)$ as electrolyte.

We applied Square Wave (SW) voltammetry to obtain the discrimination model, combining all pulse techniques' best aspects. It shows a lesser background current that results in a higher sensibility between all voltammetry techniques. Figure 2 shows the behavior of all cutting agents studied when the BDD electrode is applied. Note that some of them manifested specifics responses: aminopyrine has three electronic transfer processes, with $E_{o x}$ of $0.4,0.6$, and $1.2 \mathrm{~V}$; acetaminophen shows a low value to the redox process, being close to $0.5 \mathrm{~V}$; and three compounds, lidocaine, levamisole, and caffeine, present high $E_{o x}$ values of $1.1,1.3$ and $1.4 \mathrm{~V}$, respectively. However, three compounds, procaine, benzocaine, and phenacetin, showed a slight difference in the redox process's values, all-around $0.9 \mathrm{~V}$. 


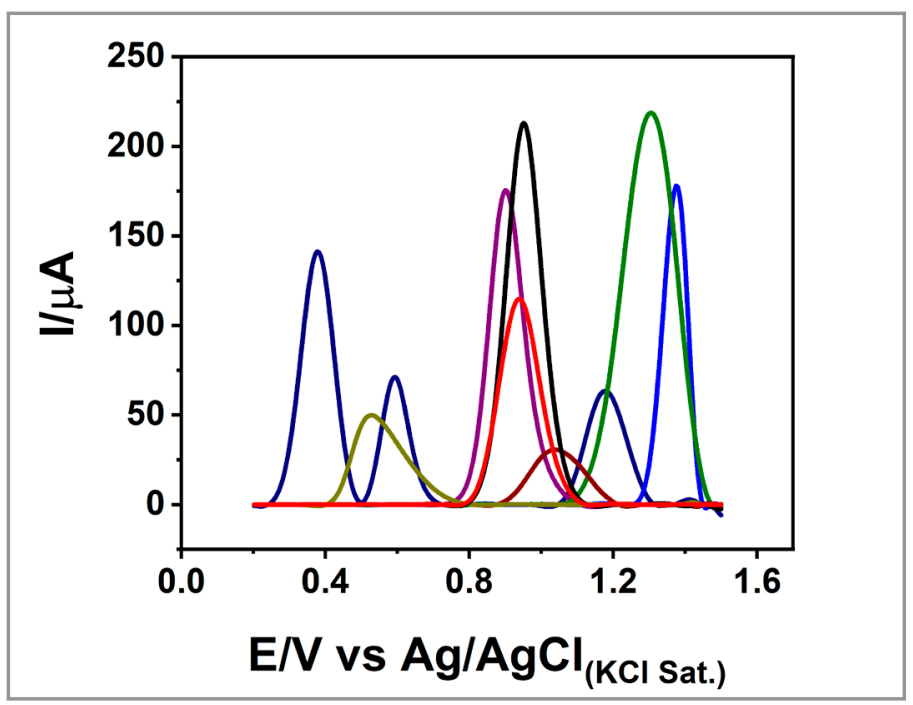

Figure 2. SW voltammograms in presence of phenacetin (black), procaine (red), caffeine (blue), levamisole (green), acetaminophen (yellow), aminopyrine (dark blue), lidocaine (wine) and benzocaine (purple) at $1 \mathrm{mmol} \mathrm{L}^{-1}$. SWV Parameters: $t_{e}=10 \mathrm{~s}, E_{i}=0.0 \mathrm{~V}, E_{f}=1.7 \mathrm{~V}, \Delta E_{s}=5 \mathrm{mV}, \Delta E_{A}=25$ $\mathrm{mV}, f=30 \mathrm{~Hz}$.

The current values for potential were used as input data to the chemometric technique, PCA. In the beginning, the statistical model was constructed using the absolute current value without any pretreatment. However, the model can classify or discriminate none of the groups due to the reflection of the concentration-effect in the current values when the cutting agents were studied in different concentrations (data not shown). Or rather, once an increase of the compound concentration promotes a current value increment, the model could not identify any pattern between the cutting agent groups and overlapped all the samples. Aiming to eliminate this problem, the current values were treated mathematically, using baseline correction and normalization between 0 and 1 as reported in the literature [19], before being inputted to the chemometric tool. Figure 3 shows the study applying the sensor to discriminate the cutting agents over different concentrations, varying between 0.1 and $1 \mathrm{mmol} \mathrm{L}^{-1}$. The PCA model could satisfactorily discriminate six groups of cutting agents through the considerable dispersion of levamisole samples. This result shows significant differences between voltammetric behaviors from five groups over the similarities between redox processes of procaine, benzocaine, and phenacetin. Then, those three groups' characteristics promote a model comprehension as only one big group, with a dense overlap of procaine's and benzocaine's groups. Additionally, the mixture of these six groups well discriminated here was evaluated two in a composition 1:1, and good discrimination was observed in the PCA score plots, data not shown.

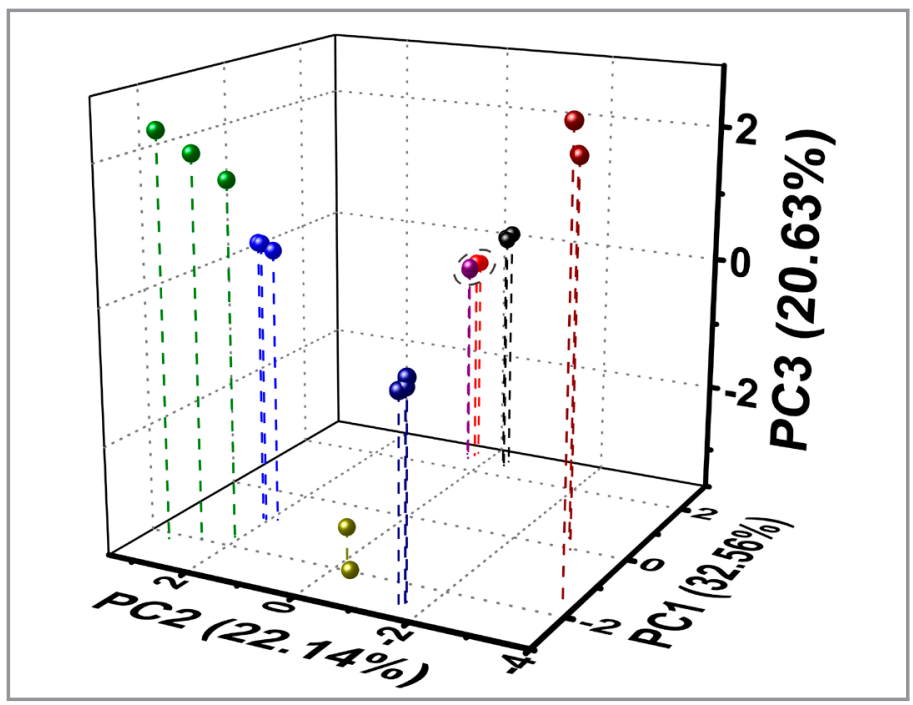

Figure 3. PCA scores plot using pre-processed current values recorded by SW voltammetry with BDD electrode in the presence of phenacetin (black), procaine (red), caffeine (blue), levamisole (green), acetaminophen (yellow), aminopyrine (dark blue), lidocaine (wine) and benzocaine (purple). Concentration range $=0.1$ to $1.0 \mathrm{mmol} \mathrm{L}^{-1}$. 


\section{Colorimetric experiments}

In analytical chemistry, colorimetric uses color intensity and variation to identify and measure the presence and/or concentration. Commonly, spectrophotometry techniques based in Lambert-Beer register the chemical information through colorimetric signals. However, these classic instrumentations require complex and equipped lab. The colorimetric spot test method of analysis is quick, simple, and, due to its instant answer and easy-to-use procedure, this type of sensing has been used in several areas of study $[15,18-24]$ in the last years. The molecular recognition applying an array of colorimetric reactions was started by Dr. Suslick $[25,26]$. The employed reactions are generally based on acid-base, Van der Waals interaction, adsorption; precipitation; and others. This report presents the development of a colorimetric method based on a paper spot test to classify and discriminate eight cutting agents commonly added to cocaine seized samples.

Initially, several reactions were tested applying the cutting agents simultaneously, and some were taken from the literature [27-30]. Thus, 35 reactions using eight different reactant mixtures were chosen to discriminate the eight targets satisfactorily. Figure 4 shows the RGB extracted color representation using the paper-based colorimetric device when the reactions are applied to each cutting agent, and analytical blank, at $10 \mathrm{mmol} \mathrm{L}^{-1}$. Only employing eye visualization is impossible to identify the specific pattern of each cutting agent to classify them. Thereby, chemometric techniques are powerful tools when extensive data analysis is performed. In this case, 105 variables (35 reactions over 3 channels) were used as input data to the PCA model shown in Figure 5. The PCA model could satisfactorily discriminate all the nine groups, eight cutting agents, and analytical blank without any misclassified sample or group superposition. Although the manual technique to apply the reagents and analytes, the unsupervised pattern rightly recognized all the replicate samples, indicating the robustness of the developed method.

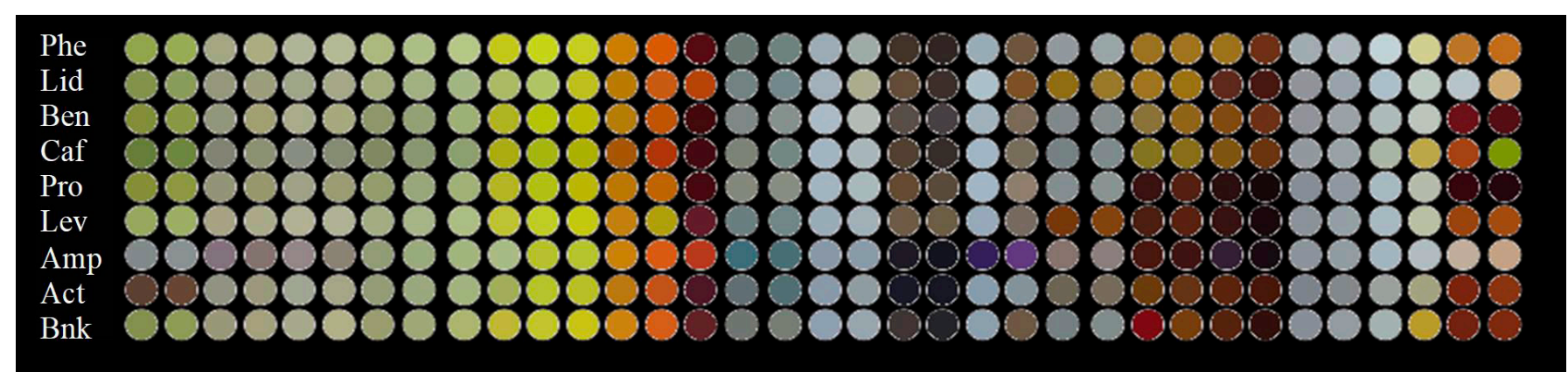

Figure 4. RBG in color representation in the cutting agents' presence at $10.0 \mathrm{mmol} \mathrm{L}^{-1}$ after 5 min of reaction. Reaction 1 to 35 from left to right.

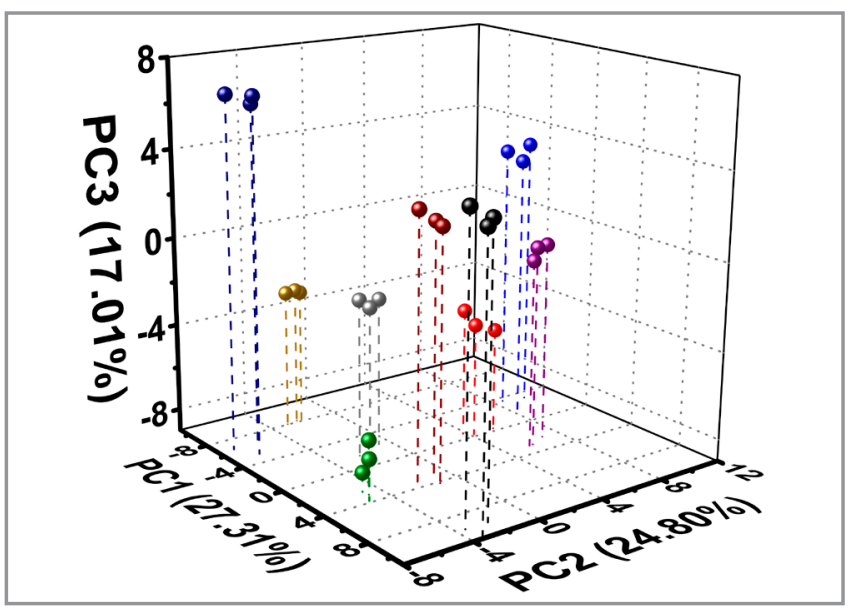

Figure 5. PCA scores plot using RGB values extracted in absence, blank (gray), and presence of phenacetin (black), procaine (red), caffeine (blue), levamisole (green), acetaminophen (yellow), aminopyrine (dark blue), lidocaine (wine) and benzocaine (purple) at $10.0 \mathrm{mmol} \mathrm{L}^{-1}$. 
They succeeded in detecting and discriminating the cutting agents in one concentration, an experiment to test the method potential when the compounds are present in a range of concentrations $(1,5$, and 10 $\mathrm{mmol} \mathrm{L}^{-1}$ ) were performed to reconstruct the reality with higher quality. Unfortunately, the same problem previously faced applying different cutting agent concentrations using SWV was obtained using RGB values as input data. Once varying the concentration value changes the intensity of color and the color itself, the model misclassified all the samples making a chaotic dispersion of the groups (data not shown). Due to the impossibility of creating an RGB pattern using untreated values when the compound is applied in different concentrations, mathematical techniques of data treatment could be employed to deal with this problem. Therefore, the RGB values extracted were linearly regressed, as reported in the experimental section, and their slope values were used as input data to construct the discriminative model. Worth mentioning, the input data was 105 variables of 35 slope values (one by reaction) to each channel (R, $G$, and B). Figure 6 shows the PCA plot obtained with the eight groups adequately discriminated against, without any misclassified sample or group superposition. This good result shows the great potentiality of the developed method for classifying unknown cocaine samples based on the cutting agent presence.

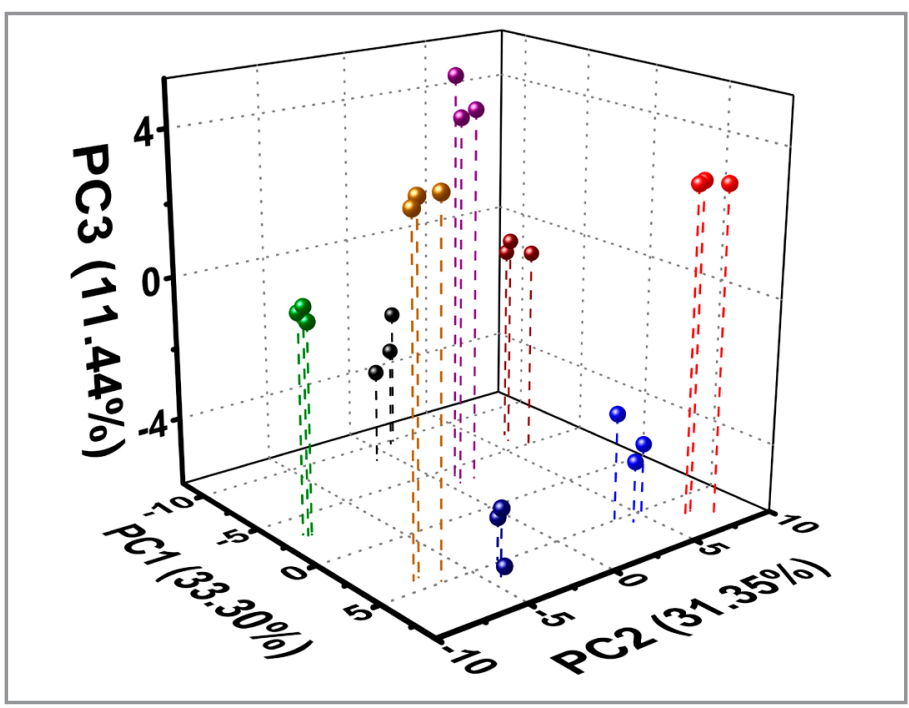

Figure 6. PCA scores plot using slopes values of RGB analytical curves in the presence of phenacetin (black), procaine (red), caffeine (blue), levamisole (green), acetaminophen (yellow), aminopyrine (dark blue), lidocaine (wine), and benzocaine (purple). Concentration range $=1.0$ to $10.0 \mathrm{mmol} \mathrm{L}^{-1}$.

\section{CONCLUSIONS}

This study shows successful electronic tongue applications to identify and classify the cutting agents individually in seized cocaine samples, aiming to determine the drug's chemical fingerprinting, demonstrating two good candidates for forensic analysis. The first device combines voltammetric technique, while the other applied colorimetric detection to chemometric data analysis. Both developed e-tongues set the main idea of first screening at the seizure moment, without the necessity of any complex equipment or sample pre-treatment. The proposed devices gather important characteristics to this field, such as fast, simple, easy-to-use, and low-cost compared to the classic analysis. In terms of fabrications, the sensor to the voltammetric device is commonly commercialized and accessible.

On the other hand, the colorimetric paper device is manually constructed by applying all reagents and targets using automatic pipettes, which may cause a robustness problem. However, nowadays, molecular printing is a growing field of study and might transform the manufacture of paper-based sensors. About the detection, the voltammetric e-tongue is portable to the remote analysis, though the necessity of a specific instrument. Simultaneously, the colorimetric approach includes one of the most used technology globally, a smartphone, which could be handled by any person and in any place. Both extracted data were analyzed using a chemometric method of pattern recognition, PCA. Each studied cutting agent's unique pattern was successfully obtained to the colorimetric device without any misclassified sample or group overlapped. On 
the other hand, the voltammetric detection could discriminate only six of eight groups due to three studied compounds (procaine, benzocaine, and phenacetin). Still, it seems to be more promising in initial studies for the discrimination of cutting agents mixture.

\section{Conflict of Interest}

The authors certify that they have no affiliations with or involvement in any organization or entity with any financial interest (such as honoraria; educational grants; participation in speakers' bureaus; membership, employment, consultancies, stock ownership, or other equity interest; and expert testimony or patent-licensing arrangements), or non-financial interest (such as personal or professional relationships, affiliations, knowledge or beliefs) in the subject matter or materials discussed in this manuscript.

\section{Acknowledgements}

This research was supported by São Paulo Research Foundation (FAPESP) [Grant numbers: 2017/10522-5, 2018/08782-1, 2019/16491-0], "Coordenação de Aperfeiçoamento de Pessoal de Nível Superior" (CAPES) [Pró-Forenses Edital 25/2014] and "Conselho Nacional de Desenvolvimento Científico e Tecnológico" (CNPq) [Grant Number: 305605/2017-8 and 302839/2020-8].

\section{REFERENCES}

1. https://wdr.unodc.org/wdr2020/index.html [Accessed 07 April 2021].

2. https://www.unodc.org/pdf/publications/report_st-nar-35.pdf 2005 [Accessed 07 April 2021].

3. https://www.unodc.org/unodc/en/scientists/drug-characterization-and-impurity-profiling---backgroundand-concepts.html [Accessed 07 April 2021].

4. Caligiorne, S. M.; Marinho, P. A. Revista Criminalística e Medicina Legal, 2016, 1 (1), pp 34-45 (http:// revistacml.com.br/wp-content/uploads/2017/01/RCML01-06.pdf).

5. Cole, C.; Jones, L.; McVeigh, J.; Kicman, A.; Syed, Q.; Bellis, M. Drug Test. Anal., 2011, 3 (2), pp 89-96 (https://doi.org/10.1002/dta.220).

6. Vlasov, Y.; Legin, A.; Rudnitskaya, A.; Di Natale, C.; D’Amico, A. Pure Appl. Chem., 2005, 77 (11), pp 1965-1983 (https://doi.org/10.1351/pac200577111965).

7. Wei, Z.; Yang, Y.; Wang, J.; Zhang, W.; Ren, Q. J. Food Eng., 2018, 217, pp 75-92 (https://doi. org/10.1016/j.jfoodeng.2017.08.005).

8. de Morais, T. C. B.; Rodrigues, D. R.; Souto, U. T. C. P.; Lemos, S. G. Food Chem., 2019, 273, pp 31-38 (https://doi.org/10.1016/j.foodchem.2018.04.136).

9. Wang, J.; Zhu, L.; Zhang, W.; Wei, Z. Anal. Chim. Acta, 2019, 1050, pp 60-70 (https://doi.org/10.1016/j. aca.2018.11.016).

10. Chapman, J.; Truong, V. K.; Elbourne, A.; Gangadoo, S.; Cheeseman, S.; Rajapaksha, P.; Latham, K.; Crawford, R. J.; Cozzolino, D. Chemical Reviews, 2020, 120 (13), pp 6048-6069 (https://doi. org/10.1021/acs.chemrev.9b00616).

11. Zabadaj, M.; Szuplewska, A.; Kalinowska, D.; Chudy, M.; Ciosek-Skibińska, P. Sens. Actuators B Chem., 2018, 272, pp 264-273 (https://doi.org/10.1016/j.snb.2018.05.137).

12. Saidi, T.; Moufid, M.; Zaim, O.; El Bari, N.; Bouchikhi, B. Meas. J. Int. Meas. Confed., 2018, 115, pp 178-184 (https://doi.org/10.1016/j.measurement.2017.10.044).

13. Wesoły, M.; Ciosek-Skibińska, P. Sens. Actuators B Chem., 2018, 267, pp 570-580 (https://doi. org/10.1016/j.snb.2018.04.050).

14. Guo, T.; Yin, T.; Ma, Z.; Wang, Z.; Sun, X.; Yuan, W. IFAC-PapersOnLine, 2018, 51 (17), pp 683-688 (https://doi.org/10.1016/j.ifacol.2018.08.117).

15. Salles, M. O.; Meloni, G. N.; de Araujo, W. R.; Paixão, T. R. L. C. Anal. Methods, 2014, 6 (7), pp 20472052 (https://doi.org/10.1039/C3AY41727A).

16. Sant'Ana, L. D.; de Sousa, V. C.; dos Santos, F. R.; Sabino, B. D.; Cardoso, A.; de Lima, M. E. F.; Castro, R. N. Quim. Nova, 2019, 42 (4), pp 379-386 (https://doi.org/10.21577/0100-4042.20170346). 
17. Villesen, P.; Nielsen, L. S. Sci. Rep., 2017, 7 (1), pp 1-8 (https://doi.org/10.1038/s41598-017-12042-x). 18. Botelho, É. D.; Cunha, R. B.; Campos, A. F. C.; Maldaner, A. O. J. Braz. Chem. Soc., 2014, 25 (4), pp 611-618 (https://dx.doi.org/10.5935/0103-5053.20140008).

19. Selva, T. M. G.; Paixão, T. R. L. C. New J. Chem., 2016, 40 (3), pp 2514-2520 (https://doi.org/10.1039/ C5NJ03524D).

20. Martinez, A. W.; Phillips, S. T.; Butte, M. J.; Whitesides, G. M. Angew. Chemie - Int. Ed., 2007, 46 (8), pp 1318-1320 (https://doi.org/10.1002/anie.200603817).

21. Dini, F.; Paolesse, R.; Filippini, D.; D’Amico, A.; Lundström, I.; Di Natale, C. Procedia Engineering, 2010, 5, pp 1228-1231 (https://doi.org/10.1016/j.proeng.2010.09.334).

22. Eaidkong, T.; Mungkarndee, R.; Phollookin, C.; Tumcharern, G.; Sukwattanasinitt, M.; Wacharasindhu, S. J. Mater. Chem., 2012, 22, pp 5970-5977.

23. Jokerst, J. C.; Adkins, J. A.; Bisha, B.; Mentele, M. M.; Goodridge, L. D.; Henry, C. S. Anal. Chem., 2012, 84, 6, pp 2900-2907 (https://doi.org/10.1021/ac203466y).

24. Rattanarat, P.; Dungchai, W.; Cate, D.; Volckens, J.; Chailapakul, O.; Henry, C.S. Anal. Chem., 2014, 86 (7), pp 3555-3562 (https://doi.org/10.1021/ac5000224).

25. Suslick, K. S.; Rakow, N. A.; Sen, A. Tetrahedron, 2004, 60 (49), pp 11133-11138 (https://doi. org/10.1016/j.tet.2004.09.007).

26. Janzen, M. C.; Ponder, J. B.; Bailey, D. P.; Ingison, C. K.; Suslick, K. S. Anal. Chem., 2006, 78 (11), pp 3591-3600 (https://doi.org/10.1021/ac052111s).

27. Wisniak, J. Revista CENIC Ciencias Biológicas, 2018, 48 (1), pp 40-48 (https://revista.cnic.cu/index. $\mathrm{php/RevBiol/article/view/24).}$

28. Sims, F. H.; Horn, C. Am. J. Clin. Pathol., 1958, 29 (5), pp 412-417 (https://doi.org/10.1093/ ajcp/29.5.412).

29. Raal, A.; Meos, A.; Hinrikus, T.; Heinämäki, J.; Romāne, E.; Gudienè, V.; Jak Tas, V.; Koshovyi, O.; Kovaleva, A.; Fursenco, C.; et al. Pharmazie, 2020, 75 (7), pp 299-306 (https://pubmed.ncbi.nlm.nih. gov/32635970/).

30. Arnab, A.; Goyal, A.; Middha, S. J. Nat. Pharm., 2010, 1 (1), pp 40-45 (https://www. semanticscholar.org/paper/Evaluation-of-the-DPPH-radical-scavenging-activity\%2C-Arnab-Goyal/ cb6ea2c9f7220c0f4dded5ee9c59cfeea67bc90c). 